\title{
Effect of fatty acid chain length and saturation on the gastrointestinal handling and metabolic disposal of dietary fatty acids in women
}

\author{
Amanda E. Jones, Michael Stolinski, Ruth D. Smith, Jane L. Murphy and Stephen A. Wootton* \\ Institute of Human Nutrition, University of Southampton, Southampton SO16 6YD, UK
}

(Received 25 November 1997 - Revised 22 July 1998 - Accepted 3 August 1998)

\begin{abstract}
The gastrointestinal handling and metabolic disposal of $\left[1-{ }^{13} \mathrm{C}\right]$ palmitic acid, $\left[1-{ }^{13} \mathrm{C}\right]$ stearic acid and $\left[1{ }^{13} \mathrm{C}\right]$ oleic acid administered within a lipid-casein-glucose-sucrose emulsion were examined in normal healthy women by determining both the amount and nature of the ${ }^{13} \mathrm{C}$ label in stool and label excreted on breath as ${ }^{13} \mathrm{CO}_{2}$. The greatest excretion of ${ }^{13} \mathrm{C}$ label in stool was in the stearic acid trial $(9 \cdot 2 \%$ of administered dose) whilst comparatively little label was observed in stool in either the palmitic acid ( $1.2 \%$ of administered dose) or oleic acid (1.9\% of administered dose) trials. In both the palmitic acid and oleic acid trials, all of the label in stool was identified as being present in the form in which it was administered (i.e. $\left[{ }^{13} \mathrm{C}\right]$ palmitic acid in the palmitic acid trial and $\left[{ }^{13} \mathrm{C}\right]$ oleic acid in the oleic acid trial). In contrast, only $87 \%$ of the label in the stool in the stearic acid trial was identified as $\left[{ }^{13} \mathrm{C}\right]$ stearic acid, the remainder was identified as $\left[{ }^{13} \mathrm{C}\right]$ palmitic acid which may reflect chain shortening of $\left[1{ }^{13} \mathrm{C}\right]$ stearic acid within the gastrointestinal tract. Small, but statistically significant, differences were observed in the time course of recovery of ${ }^{13} \mathrm{C}$ label on breath over the initial $9 \mathrm{~h}$ of the study period (oleic acid $=$ palmitic acid $>$ stearic acid). However, when calculated over the $24 \mathrm{~h}$ study period, the recovery of the label as ${ }^{13} \mathrm{CO}_{2}$ was similar in all three trials (approximately $25 \%$ of absorbed dose). These results support the view that chain length and degree of unsaturation may influence the gastrointestinal handling and immediate metabolic disposal of these fatty acids even when presented within an emulsion.
\end{abstract}

Fatty acids: Postprandial lipid metabolism: Stable isotopes

Dietary lipids, particularly saturated fatty acids, are directly related to both the circulating levels of lipids and lipoproteins and the development of non-communicable diseases such as cardiovascular disease, insulin resistance and obesity. Although the relationship linking dietary lipid with these diseases now focuses on measurements of circulating lipids in the postprandial state (Karpe, 1997) little is known about factors which determine the handling of dietary lipid and how these influence postprandial events. Differences in the way that fatty acids are handled, both in terms of absorption across the gastrointestinal (GI) tract and partitioning towards either oxidation or storage, may contribute to the contrasting metabolic consequences of diets of differing fatty acid composition. For example, the apparently neutral effects on plasma cholesterol levels of diets rich in stearic acid, in comparison with the hypercholesterolaemic effects of diets rich in saturated fatty acids of shorter chain lengths (Keys et al. 1957, 1965; Hegsted et al. 1965), may be partly attributable to comparatively poor absorption and oxidation of stearic acid (Kritchevsky, 1994).
The most direct approach to examine the handling of dietary lipid across the GI tract and subsequent metabolic partitioning is to apply $\mathrm{C}$ tracer methodologies, where absorption is derived from the excretion of label measured within stool and oxidation from the recovery of label on breath as labelled $\mathrm{CO}_{2}$. Tracer studies in rodents suggest that both absorption of dietary lipid (Bloom et al. 1951; Kirschner \& Harris, 1961; Ockner et al. 1972; Clarke et al. 1977) and partitioning towards oxidation or retention (Mead et al. 1956; Lynn \& Brown, 1959; Kirschner \& Harris, 1961; Goransson, 1965; Dupont, 1966; Leyton et al. 1987) are influenced by fatty acid chain length and degree of unsaturation. However, there is limited evidence that similar effects occur in man. In the only study which has examined both the GI handling and oxidation of fatty acids of differing chain length and saturation, Jones et al. (1985a) found that whilst the absorption of $\left[1-{ }^{13} \mathrm{C}\right]$ oleic acid and $[1-$ ${ }^{13} \mathrm{C}$ linoleic acid was high $(97 \cdot 2$ and $99.9 \%$ of administered dose respectively), $\left[1-{ }^{13} \mathrm{C}\right]$ stearic acid was poorly absorbed (78.0\% of administered dose). In addition, they also reported differences in the oxidation of these fatty acids; 
the greatest oxidation was seen for $\left[1-{ }^{13} \mathrm{C}\right]$ oleic acid $(15 \cdot 1 \%$ of absorbed dose), followed by $\left[1-{ }^{13} \mathrm{C}\right]$ linoleic acid $(10 \cdot 2 \%$ of absorbed dose) whilst there was minimal oxidation of [1${ }^{13}$ C]stearic acid $(2.9 \%$ of absorbed dose) (Jones et al. 1985b). Using a similar approach we determined the GI handling and metabolic disposal of $\left[1-{ }^{13} \mathrm{C}\right]$ palmitic acid (Murphy et al. 1995). We found that whilst the absorption of $\left[1-{ }^{13} \mathrm{C}\right]$ palmitic acid was similar to that of $\left[1-{ }^{13} \mathrm{C}\right]$ stearic acid reported previously ( $85.7 \%$ of administered dose), there was considerably greater oxidation $(16.9 \%$ of absorbed dose). Thus, it appears that palmitic acid behaves like stearic acid in terms of absorption, yet it behaves more like oleic acid in terms of oxidation.

In both these studies the labelled fatty acids were administered by simply mixing the free acid with fat in the test meal. One possible explanation for the poor absorption of the saturated fatty acids is that as they are crystalline solids at body temperature they may have been less able to form micelles within the lumen, thereby limiting absorption. On the basis of the rate of appearance of labelled fatty acids in the circulation, it has been proposed that absorption of labelled fatty acids, particularly saturated fatty acids, could be improved by administering fatty acids within a lipid-casein-glucose-sucrose emulsion (Emken et al. 1993). However, this suggestion has never been tested directly by measuring the excretion of labelled fatty acids within stool. The aim of the present study was to examine both the GI handling and metabolic disposal of [1$\left.{ }^{13} \mathrm{C}\right]$ palmitic acid, $\left[1-{ }^{13} \mathrm{C}\right]$ stearic acid and $\left[1{ }^{13} \mathrm{C}\right]$ oleic acid administered within a lipid-casein-glucose-sucrose emulsion to normal, healthy women. Absorption was determined by measuring both the total amount of ${ }^{13} \mathrm{C}$ label excreted in stool and also the nature of the species bearing the ${ }^{13} \mathrm{C}$ label within stool. Oxidation was determined by measuring the excretion of ${ }^{13} \mathrm{C}$ label on breath as ${ }^{13} \mathrm{CO}_{2}$. These fatty acids were selected as they are the predominant saturated and monounsaturated fatty acids in the UK diet (Gregory et al. 1990) and also in order to determine whether stearic acid is handled differently from either palmitic acid or oleic acid.

\section{Methods}

\section{Subjects}

Three groups of six or seven normal, healthy, young women participated in the study. The groups were matched for age (20-31 years), body size (weight $46 \cdot 5-84.5 \mathrm{~kg}$; height $1.58-1.79 \mathrm{~m}$ ), body composition (BMI $18.4-27.0 \mathrm{~kg} / \mathrm{m}^{2}$; body fat $19 \cdot 0-32.3 \%$ ) and the use of oral contraceptives. The subjects were members of staff at the University of Southampton. Informed consent was obtained from the subjects and the study was approved by the Ethical Committee of Southampton and South West Hampshire Health Commission.

\section{Study protocol}

After an overnight fast subjects consumed either [1$\left.{ }^{13} \mathrm{C}\right]$ palmitic acid, $\left[1-{ }^{13} \mathrm{C}\right]$ stearic acid or $\left[1-{ }^{13} \mathrm{C}\right]$ oleic acid at a dose of $10 \mathrm{mg} / \mathrm{kg}$ body weight (99 atom percent excess;
Masstrace, Woburn, MA, USA). The labelled fatty acids were heated to $85^{\circ}$ in a mixture of double cream and olive oil and made into an emulsion with a mixture of casein, glucose and sucrose dissolved in water kept above $85^{\circ}$, according to E. Emken (personal communication). The emulsion was flavoured with chocolate milk-shake powder (Nesquik, Nestlé, Vevey, Switzerland) containing permitted emulsifiers to improve palatability and stability. The emulsion was consumed with $120 \mathrm{~g}$ white bread, $20 \mathrm{~g}$ strawberry jam and $10 \mathrm{~g}$ Flora margarine which, together with the emulsion, constituted the test meal: $3007 \mathrm{~kJ}, 30 \cdot 0 \mathrm{~g}$ lipid, $97.4 \mathrm{~g}$ carbohydrate and $19.9 \mathrm{~g}$ protein. The fatty acid composition of the test meal was $(\mathrm{g} / 100 \mathrm{~g}$ total fatty acids): saturated fatty acids 43 ; monounsaturated fatty acids 38 ; polyunsaturated fatty acids 19 . Breath samples were collected into breath collection bags before label administration to measure baseline ${ }^{13} \mathrm{C}$ excretion on breath and then at hourly intervals for $10 \mathrm{~h}$ and again at 15 and $24 \mathrm{~h}$ after label administration. Specimen breath samples were transferred into evacuated tubes (Exetainers; Labco, High Wycombe, Bucks., UK) for analysis in duplicate. Whole-body breath $\mathrm{CO}_{2}$ excretion was measured by indirect calorimetry (GEM; Europa Scientific Ltd, Crewe, Cheshire, UK) at the same time points as the breath samples. Subjects remained seated or supine and were under constant supervision at the Clinical Nutrition and Metabolism Unit at Southampton General Hospital for the duration of the initial $9 \mathrm{~h}$ of the study. No additional foods or liquids, except for bottled mineral water, were permitted during this period. After $9 \mathrm{~h}$ subjects consumed a fixed meal, which contained no foods naturally enriched with ${ }^{13} \mathrm{C}$, before leaving the Unit. The subjects were unsupervised over the remaining period of the study (i.e. 10-24h) and the 10,15 and $24 \mathrm{~h}$ breath samples were collected at home.

A baseline stool sample was collected on the day before the trial to measure baseline ${ }^{13} \mathrm{C}$ excretion in stool. Thereafter, all stools passed were collected for $5 \mathrm{~d}$ following label administration. The methodology for collecting and processing of stools has been described previously (Murphy et al. 1995). The subjects were instructed to avoid consuming foods naturally enriched with ${ }^{13} \mathrm{C}$ (e.g. corn (maize) products, cane sugar) for at least $2 \mathrm{~d}$ before the study and over the $5 \mathrm{~d}$ study period. All studies were performed during the week after menstruation.

\section{Measurement of ${ }^{13} \mathrm{C}$ enrichment in stool and breath}

Enrichment of ${ }^{13} \mathrm{C}$ in stool and on breath as ${ }^{13} \mathrm{CO}_{2}$ was determined by continuous flow-isotope ratio mass spectrometry (20-20 stable isotope analyser; Europa Scientific Ltd) as detailed previously (Murphy et al. 1995). The enrichment of ${ }^{13} \mathrm{C}$ in each sample was calculated from the increase in the ${ }^{13} \mathrm{CO}_{2}:{ }^{12} \mathrm{CO}_{2}$ ratio compared with that obtained from a working reference standard (beet sugar and $50 \mathrm{ml} \mathrm{CO} / 1$ for samples of stool and breath respectively). The results were expressed as the 'del per mil' (parts per thousand) difference between ${ }^{13} \mathrm{CO}_{2}:{ }^{12} \mathrm{CO}_{2}$ ratios of the samples and the reference standard Pee Dee Belemnite (PDB) as defined by Craig (1957) $\left({ }^{13} \mathrm{C}_{\mathrm{PDB}}, \%\right.$ ). The proportion of administered ${ }^{13} \mathrm{C}$ label in stool was calculated according to the formula of Schoeller et al. (1981). The proportion of ${ }^{13} \mathrm{C}$ label excreted 
on breath as ${ }^{13} \mathrm{CO}_{2}$ was expressed as a percentage of the administered ${ }^{13} \mathrm{C}$ label per hour and as the cumulative percentage dose excreted over $24 \mathrm{~h}$.

The nature of the ${ }^{13} \mathrm{C}$ label in stool was determined by gas chromatography-isotope ratio mass spectrometry (GCIRMS) (Orchid Gas Chromatograph Interface Module and 20-20 stable isotope analyser; Europa Scientific Ltd) as described previously (Stolinski et al. 1997). Lipids were extracted from ${ }^{13} \mathrm{C}$-enriched stools by modification of the method of Folch et al. (1957) saponified, methylated, evaporated to dryness and taken up in hexane for analysis by GC-IRMS.

\section{Substrate oxidation}

Net substrate oxidation was estimated from gaseous exchange measurements made by indirect calorimetry (Frayn, 1983). Estimates of net lipid and carbohydrate oxidation were made in the postabsorptive state and over $9 \mathrm{~h}$ following consumption of the test meal. $\mathrm{N}$ oxidation was assumed from measurements of the protein intake of individual subjects; inaccuracies in assumed $\mathrm{N}$ excretion of up to $30 \%$ would have no significant effect on fat and carbohydrate oxidation values.

\section{Statistical analysis}

The results are reported as means and standard deviations (SD) in the text with individual data represented graphically to illustrate inter-individual variability. Statistical comparisons between the trials were performed using ANOVA with subsequent Tukey's post-hoc tests. Differences between means were considered statistically significant where $P<0.05$.

\section{Results}

\section{Gastrointestinal handling}

Total excretion of ${ }^{13} \mathrm{C}$ label in stool over $5 \mathrm{~d}$ following administration of the labelled fatty acids is shown in Fig. 1. The values for excretion of ${ }^{13} \mathrm{C}$ label within stool were similar for the palmitic acid (1.2 (SD 0.9) \% of administered dose) and oleic acid trials (1.9 (SD 2.1) \% of administered dose; NS). In contrast, about five times as much ${ }^{13} \mathrm{C}$ label was excreted within stool for the stearic acid trial (9.2 (SD $4.4) \%$ of administered dose; $P<0.05$ ). Greater variability was also observed than for either the palmitic or oleic acid trials (range $3 \cdot 2-14.2 \%$ of administered dose compared with $<5 \%$ ). In all three trials the greatest levels of ${ }^{13} \mathrm{C}$ enrichment within stool were observed within 2-3 d following label administration, with the ${ }^{13} \mathrm{C}$ enrichment of stools equivalent to baseline levels by day 5 ( -24 to $-27 \%$ ) .

The fatty acid profiles of stool samples, as determined by GC-IRMS, were similar for all three trials, with over $95 \%$ of the fatty acids identified as palmitic acid (40\%), stearic acid $(30 \%)$, oleic acid $(20 \%)$ and linoleic acid $(5 \%)$. Identifying the species bearing the ${ }^{13} \mathrm{C}$ label within stool demonstrated that the ${ }^{13} \mathrm{C}$ label was restricted to $\left[{ }^{13} \mathrm{C}\right]$ palmitic acid for the palmitic acid trial and to $\left[{ }^{13} \mathrm{C}\right]$ oleic acid for the oleic acid trial (i.e. the same as the

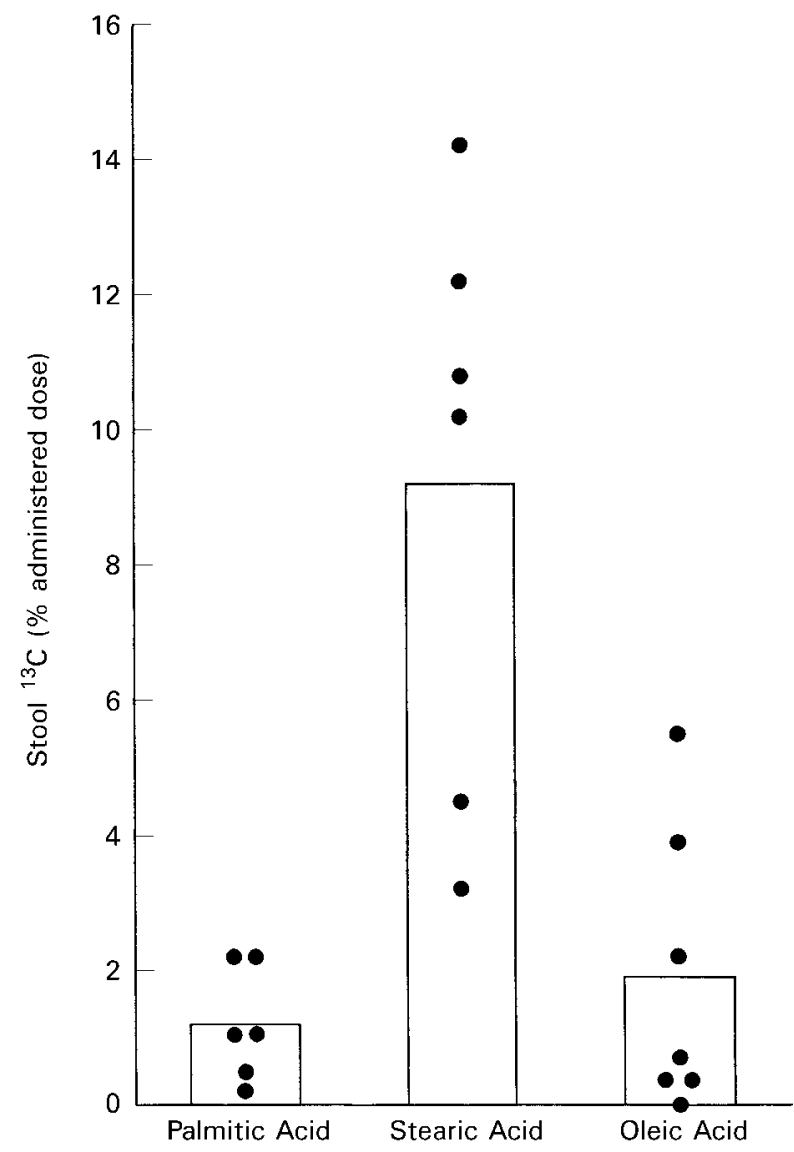

Fig. 1. Excretion of ${ }^{13} \mathrm{C}$ label in stool by healthy female subjects over $5 \mathrm{~d}\left(\%\right.$ administered dose) following administration of $\left[1{ }^{13} \mathrm{C}\right]$ palmitic acid, $\left[1{ }^{13} \mathrm{C}\right]$ stearic acid or $\left[1-{ }^{13} \mathrm{C}\right]$ oleic acid within a lipid-caseinglucose-sucrose emulsion. The bar represents the mean value for the trial and the circles represent individual subjects.

species that was consumed). In contrast, for the stearic acid trial, two species were identified as bearing the ${ }^{13} \mathrm{C}$ label in every enriched stool sample: $\left[{ }^{13} \mathrm{C}\right]$ stearic acid (mean ${ }^{13} \mathrm{C}$ enrichment $204 \cdot 1 \%$ ) and $\left[{ }^{13} \mathrm{C}\right]$ palmitic acid (mean ${ }^{13} \mathrm{C}$ enrichment $-3 \cdot 8 \%$ o). Approximately $87 \%$ of the ${ }^{13} \mathrm{C}$ label within stool was $\left[{ }^{13} \mathrm{C}\right]$ stearic acid, equivalent to $6 \cdot 8$ (SD 3.9) $\%$ of administered dose, whilst $13 \%$ of the ${ }^{13} \mathrm{C}$ label was identified as $\left[{ }^{13} \mathrm{C}\right]$ palmitic acid, equivalent to $0 \cdot 9$ (SD 0.3) \% of administered dose.

\section{Metabolic disposal}

The excretion of ${ }^{13} \mathrm{C}$ label on breath as ${ }^{13} \mathrm{CO}_{2}$ was expressed as a percentage of absorbed dose which takes into account losses of ${ }^{13} \mathrm{C}$ label within stool. The data are presented without correction for possible retention of ${ }^{13} \mathrm{CO}_{2}$ within the bicarbonate pools of the body (see p. 42). The pattern of ${ }^{13} \mathrm{CO}_{2}$ excreted on breath over $24 \mathrm{~h}$ following administration of the labelled fatty acids is shown in Fig. 2. Excretion of ${ }^{13} \mathrm{CO}_{2}$ on breath was observed from $1 \mathrm{~h}$ after consumption of the test meal, with peak enrichment values occurring between 3 and $7 \mathrm{~h}$. By $24 \mathrm{~h}$ breath ${ }^{13} \mathrm{CO}_{2}$ excretion was less than $0.5 \%$ of absorbed dose $(-23$ to $-25 \%$ ). Repeated measures ANOVA demonstrated that there were differences 


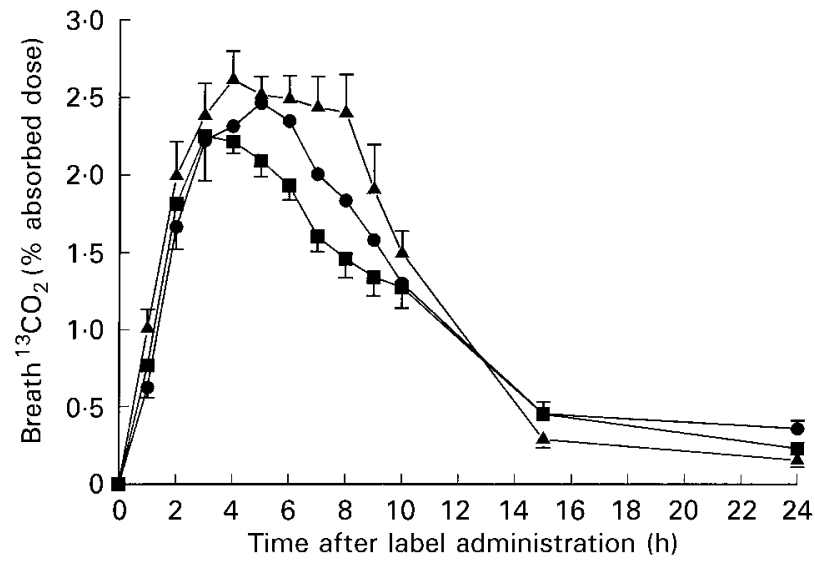

Fig. 2. Time course for the excretion of ${ }^{13} \mathrm{CO}_{2}$ on breath over $24 \mathrm{~h}(\%$ absorbed dose) following administration of $\left[1-{ }^{13} \mathrm{C}\right]$ palmitic acid $(\bullet)$, $\left[1-{ }^{13} \mathrm{C}\right]$ stearic acid $(\boldsymbol{\square})$ or $\left[1{ }^{13} \mathrm{C}\right]$ oleic acid $(\boldsymbol{\Lambda})$ within a lipid-caseinglucose-sucrose emulsion. Values are means for six or seven subjects, with their standard errors represented by vertical bars. The data are presented without correction for possible retention of ${ }^{13} \mathrm{CO}_{2}$ within the bicarbonate pools of the body (see p. 42).

in the pattern of ${ }^{13} \mathrm{CO}_{2}$ excreted on breath over time between the three trials $(P<0 \cdot 05)$. The differences were most evident between the stearic acid trial and the oleic acid trial from $5 \mathrm{~h}(P=0 \cdot 022)$ until $8 \mathrm{~h}(P=0 \cdot 007)$ after label administration. The stearic acid trial also differed from the palmitic acid trial at $8 \mathrm{~h}(P=0.026)$ but not at any other time points. Values for total ${ }^{13} \mathrm{CO}_{2}$ excretion on breath over the initial $9 \mathrm{~h}$ of the study, when subjects received no further food and were continually supervised, were similar for the palmitic acid trial (16.3 (SD 2.6) \% of absorbed dose) and the oleic acid trial (18.8 (SD 2.9) \% of absorbed dose; NS). In the stearic acid trial, breath ${ }^{13} \mathrm{CO}_{2}$ excretion (14.9 (SD 1.4) \% of absorbed dose) was lower than in the oleic acid trial $(P=0.012)$ but was not different from the palmitic acid trial. Over the complete $24 \mathrm{~h}$ period the differences became less evident, with all three trials showing similar magnitude and variability in breath ${ }^{13} \mathrm{CO}_{2}$ excretion although the general pattern was preserved (palmitic acid $25 \cdot 7$ (SD 4.4) \% of absorbed dose; stearic acid 23.6 (SD 1.1) $\%$ of absorbed dose; oleic acid $26 \cdot 8$ (SD 3.3) \% of absorbed dose; NS).

\section{Substrate oxidation}

The patterns of net lipid and carbohydrate oxidation over the controlled $9 \mathrm{~h}$ period were similar in all three trials as the only difference in the test meal was the small amount of tracer fatty acid. Compared with postabsorptive values, net lipid oxidation decreased following consumption of the test meal, with the lowest rates occurring between 1 and $3 \mathrm{~h}$ postprandially and returning to postabsorptive values by about $4-5 \mathrm{~h}$ before exhibiting slightly greater rates for the remainder of the $9 \mathrm{~h}$ period. Net carbohydrate oxidation mirrored lipid oxidation with an initial increase compared with postabsorptive values, with peak values occurring at about $1-2 \mathrm{~h}$ postprandially, returning to postabsorptive values by about $5-6 \mathrm{~h}$ then showing slightly lower rates for the remainder of the $9 \mathrm{~h}$ period. Net lipid oxidation did not differ between trials: palmitic acid trial 13.5 (SD 6.3) g/9 h; stearic acid trial 20.8 (SD 6.4) g/9 h; oleic acid trial $18 \cdot 1$ (SD 9.8) g/9 h (NS). No differences between trials in carbohydrate oxidation were observed: palmitic acid trial 81.9 (SD 12.9) g/9 h; stearic acid trial 71.7 (SD 8.5) g/9 h; oleic acid trial 88.0 (SD 26.2) g/9 h (NS). Combining net lipid oxidation with oxidation of the labelled fatty acid, as a marker of exogeneous lipid oxidation from the test meal, indicated that exogeneous lipid oxidation was about $5 \mathrm{~g} / 9 \mathrm{~h}$, accounting for one third of net lipid oxidation.

\section{Discussion}

\section{Gastrointestinal handling}

This is the first occasion on which ${ }^{13} \mathrm{C}$-labelled palmitic acid, stearic acid and oleic acid have been consumed within an emulsion in order to compare directly the GI handling and metabolic disposal of these fatty acids in human subjects. There have been only two previous studies of similar experimental design using ${ }^{13} \mathrm{C}$-labelled fatty acids against which the findings of the present study may be compared. Taken together these would suggest that the absorption of [1- ${ }^{13}$ C]palmitic acid (85\%) (Murphy et al. 1995) and [1${ }^{13}$ C]stearic acid (78\%) (Jones et al. 1985a) was poor in comparison with the almost complete absorption of [1${ }^{13}$ C]oleic and linoleic acids (Jones et al. 1985a). In both these studies the labelled fatty acids were administered by simply mixing the free acid with fat in the test meal. In the present study, we found that relatively small amounts of ${ }^{13} \mathrm{C}$ label were excreted in stool in both the palmitic acid and oleic acid trials, indicating almost complete absorption $(>98 \%)$ of both $\left[1-{ }^{13} \mathrm{C}\right]$ palmitic acid and $\left[1-{ }^{13} \mathrm{C}\right]$ oleic acid. In contrast, more ${ }^{13} \mathrm{C}$ label was excreted in stool in the stearic acid trial indicating that $\left[1-{ }^{13} \mathrm{C}\right]$ stearic acid was less well absorbed $(90 \%)$. It appears that in all three trials labelled oleic acid was almost completely absorbed irrespective of the form in which the label was administered. The absorption of both saturated fatty acids was substantially improved by administration within the emulsion in comparison with simply adding the labelled tracer to the fat within the test meal, although $\left[1-{ }^{13} \mathrm{C}\right]$ stearic acid continued to be less well absorbed than $\left[1-{ }^{13} \mathrm{C}\right]$ palmitic acid.

The reasons for the difference in absorption between [1$\left.{ }^{13} \mathrm{C}\right]$ palmitic acid and $\left[1-{ }^{13} \mathrm{C}\right]$ stearic acid remain unclear. There may be differences in the physico-chemical properties of the emulsions made with $\left[1-{ }^{13} \mathrm{C}\right]$ palmitic acid and [1$\left.{ }^{13} \mathrm{C}\right]$ stearic acid. In both trials the emulsion was made at a temperature of $85^{\circ}$, which is above the melting point of both palmitic acid $\left(64^{\circ}\right)$ and stearic acid $\left(69^{\circ}\right)$ (Gunstone et al. 1994). However, the addition of the tracer may alter other physico-chemical properties of the emulsion such as particle size, particle distribution, surface properties and the stability of the emulsion. Alternatively, the difference in absorption may reflect a true physiological difference in the way in which palmitic and stearic acids from the diet are processed within the GI tract. This could be attributable to differences in the affinity of fatty acid binding proteins for palmitic and stearic acids or a difference in the re-esterification of these fatty acids into triacylglycerol for assembly into chylomicrons. In order to resolve these issues the physico-chemical 
properties of the emulsions containing labelled fatty acids need to be determined. For example, are the different labelled fatty acids incorporated into the same particles within the emulsion and what is the nature of the labelled fatty acid within the emulsion at administration?

Although we have previously reported the nature of the species bearing the ${ }^{13} \mathrm{C}$ label within stool following administration of $\left[1-{ }^{13} \mathrm{C}\right]$ palmitic acid (Murphy et al. 1997), this is the first occasion on which such analysis has been determined for labelled stearic and oleic acids. The ${ }^{13} \mathrm{C}$ label within stool was restricted to the species that was administered in the palmitic acid and oleic acid trials. This would indicate that the ${ }^{13} \mathrm{C}$ label within stool was unabsorbed dietary residue which passed through the GI tract without any modification or metabolism. In contrast, although the majority of the ${ }^{13} \mathrm{C}$ label excreted within stool was identified as $\left[{ }^{13} \mathrm{C}\right]$ stearic acid in the stearic acid trial, small amounts of label were also identified as $\left[{ }^{13} \mathrm{C}\right]$ palmitic acid, equivalent to approximately $1 \%$ of the administered dose. Analysis of the emulsion in the stearic acid trial by GC-IRMS demonstrated that $\left[{ }^{13} \mathrm{C}\right]$ palmitic acid was not present when the emulsion was prepared. The most likely explanation is that the conversion of $\left[1-{ }^{13} \mathrm{C}\right]$ stearic acid to $\left[{ }^{13} \mathrm{C}\right]$ palmitic acid occurred during the passage through the GI tract. The conversion of $\left[1-{ }^{13} \mathrm{C}\right]$ stearic acid to $\left[{ }^{13} \mathrm{C}\right]$ palmitic acid is indicative of chain shortening by two $\mathrm{C}$ atoms (18:0 to 16:0). Chain shortening could occur by incomplete $\beta$ oxidation which would remove two $\mathrm{C}$ atoms from the carboxyl end of the fatty acid. However, as the ${ }^{13} \mathrm{C}$ label is present on the carboxyl $\mathrm{C}$ of stearic acid, incomplete $\beta$ oxidation would remove the ${ }^{13} \mathrm{C}$ label and lead to unlabelled palmitic acid. For the ${ }^{13} \mathrm{C}$ label to remain on the carboxyl $\mathrm{C}$ of the new fatty acid the chain shortening must have occurred from the methyl end of the fatty acid (i.e. omega oxidation). The site of this chain shortening is not known at present, although we consider that it is most likely to reflect bacterial metabolism within the colon. To our knowledge this is the first occasion on which chain shortening of stearic acid within the GI tract has been observed. The previous study which determined the absorption of $\left[1-{ }^{13} \mathrm{C}\right]$ stearic acid (Jones et al. 1985a) did not allow such an observation, as the authors would only have been able to measure total ${ }^{13} \mathrm{C}$ enrichment within stool. To determine which fatty acid within stool was labelled with ${ }^{13} \mathrm{C}$ would require analysis by GC-IRMS.

The GI handling of the ${ }^{13} \mathrm{C}$-labelled fatty acids in the present study is assumed to reflect that of fatty acids derived from the diet. If correct, this would suggest that chain length and degree of unsaturation both influence absorption of fatty acids, with substantially less stearic acid absorbed than either palmitic acid or oleic acid. Although these observations offer support for a possible explanation which may contribute to the apparently neutral effect of increased stearic acid intake on plasma cholesterol concentrations (Kritchevsky, 1994), the differences in absorption between fatty acids are comparatively small and are unlikely to account for differences in atherogenicity.

\section{Metabolic disposal}

Once absorbed, the partitioning of the labelled fatty acids towards either oxidation or tissue retention was determined by measuring the excretion of ${ }^{13} \mathrm{C}$ label on breath as ${ }^{13} \mathrm{CO}_{2}$. The patterns of ${ }^{13} \mathrm{CO}_{2}$ excreted on breath differed between the three trials, with the most obvious difference observed between the oleic acid and stearic acid trials between 5 and $8 \mathrm{~h}$ after label administration. During this period the excretion of ${ }^{13} \mathrm{CO}_{2}$ on breath in the oleic acid trial was more prolonged than that observed during the stearic acid trial which resulted in the total amount of ${ }^{13} \mathrm{CO}_{2}$ excreted on breath over the controlled $9 \mathrm{~h}$ period being approximately $25 \%$ greater for the oleic acid trial than the stearic acid trial. Breath ${ }^{13} \mathrm{CO}_{2}$ excretion in the palmitic acid trial was not different from either the oleic acid or stearic acid trial and followed an intermediate pattern. Over $24 \mathrm{~h}$ the differences between the three trials became less evident resulting in approximately one quarter of the absorbed dose being oxidized. This was the result of both a change in the pattern of breath ${ }^{13} \mathrm{CO}_{2}$ excretion during the later, unsupervised period of the study $(10-24 \mathrm{~h})$ with lower breath ${ }^{13} \mathrm{CO}_{2}$ excretion in the oleic acid trial than the palmitic acid and stearic acid trials and also an increased variability between subjects within each trial. The differences between the trials may have been reduced if the study had been of a repeatedtrial design so that the subjects completed all three trials. However, practical constraints meant that the subjects could not complete all three trials. In one subject who did participate in all three trials the values for oxidation of labelled fatty acid over $24 \mathrm{~h}$ were similar $\left(\left[1-{ }^{13} \mathrm{C}\right]\right.$ palmitic acid $21.9 \%$ absorbed dose; $\left[1-{ }^{13} \mathrm{C}\right]$ stearic acid $23.8 \%$ absorbed dose; $\left[1-{ }^{13} \mathrm{C}\right.$ ]oleic acid $24.4 \%$ absorbed dose).

The oxidation of $\left[1-{ }^{13} \mathrm{C}\right]$ oleic acid administered in the emulsion in the present study was similar to the oxidation of this fatty acid when it was administered as the free acid in normal, healthy men (Jones et al. 1985b). In contrast, whilst the oxidation of $\left[1-{ }^{13} \mathrm{C}\right]$ palmitic acid in the present study was similar to that observed by us previously for the free acid (Murphy et al. 1995), it was greater than that observed in either young children (Watkins et al. 1982) or normal, healthy men (Macdougall et al. 1996). However, as label excretion in stool was not measured in either study, the value for palmitic acid oxidation is expressed as a proportion of the administered dose, not absorbed dose, as in the present study. The oxidation of $\left[1-{ }^{13} \mathrm{C}\right]$ stearic acid in the present study was much greater (5-fold) than that previously reported for the oxidation of $\left[1-{ }^{13} \mathrm{C}\right]$ stearic acid administered as the free acid in normal, healthy men (Jones et al. $1985 b$ ). We believe that the differences between the studies are primarily attributable to administering the labelled fatty acid within the emulsion. However, other factors such as preceding diet (Macdougall et al. 1996) and the fatty acid composition of the test meal (Jones, 1994) may also influence the oxidation of fatty acids and may account for some of the differences between the findings of these studies.

For all three trials about one quarter of the absorbed dose was oxidized over $24 \mathrm{~h}$. Further oxidation of the labelled fatty acids may have occurred after the $24 \mathrm{~h}$ period although it could not be detected as the ${ }^{13} \mathrm{C}$ enrichment of breath at $24 \mathrm{~h}$ was at baseline levels (within $1 \%$ ). In addition this measure of oxidation may be an underestimate as not all of the ${ }^{13} \mathrm{CO}_{2}$ generated from the oxidation of the labelled fatty 
acids would have been excreted on breath; a proportion may have been retained within body pools or excreted via urine, skin or stool. Preliminary results from a study conducted by our group administering an oral bolus dose of $\mathrm{NaH}^{13} \mathrm{CO}_{3}$ to normal, healthy women demonstrated that approximately one third of the ${ }^{13} \mathrm{CO}_{2}$ generated by label oxidation may not be excreted on breath over the $24 \mathrm{~h}$ study period (Jones, 1996). Applying this correction factor to breath ${ }^{13} \mathrm{CO}_{2}$ excretion in the present study would increase the estimate of labelled fatty acid oxidation from 25 to $33 \%$ over $24 \mathrm{~h}$. Presenting the data in this way would not alter the interpretation of the results as the differences between fatty acids remain unchanged.

\section{Conclusions}

In conclusion, whilst the GI handling of $\left[1-{ }^{13} \mathrm{C}\right]$ palmitic acid and $\left[1-{ }^{13} \mathrm{C}\right]$ oleic acid were similar both in the amount and nature of the ${ }^{13} \mathrm{C}$ label excreted within the stool, the GI handling of $\left[1-{ }^{13} \mathrm{C}\right]$ stearic acid was markedly different, with lower absorption and also evidence of chain shortening of $\left[1-{ }^{13} \mathrm{C}\right]$ stearic acid within the GI tract to $\left[{ }^{13} \mathrm{C}\right]$ palmitic acid. Once absorbed, it would appear that fatty acid chain length and degree of unsaturation exert modest effects on oxidation which are most apparent in the early postprandial period. Such differences in the handling of these fatty acids may play a role in the differing metabolic effects of fatty acids on circulating lipids and lipoproteins. In particular, the poor absorption of stearic acid may contribute, at least in part, to its neutral effect on plasma cholesterol.

\section{Acknowledgements}

We thank the subjects whose cooperation was essential for the completion of this study and Mrs A. Hounslow, Miss A. Pearce, Miss J. Nurmi and Miss P. Hameen-Anttila for their assistance. This work is supported by The Ministry of Agriculture, Fisheries and Food. The Wessex Medical Trust is gratefully acknowledged.

\section{References}

Bloom B, Chaikoff IL \& Reinhardt WO (1951) Intestinal lymph as a pathway for transport of absorbed fatty acids of different chain lengths. American Journal of Physiology 166, 451-455.

Clarke SD, Romsos DR \& Leveille GA (1977) Differential effects of dietary methyl esters of long chain saturated and polyunsaturated fatty acids on rat liver and adipose tissue lipogenesis. Journal of Nutrition 107, 1170-1181.

Craig H (1957) Isotopic standards for carbon and oxygen and corrective factors for mass-spectrometric analysis of carbon dioxide. Geochemica Cosmochimica Acta 12, 133-149.

Dupont J (1966) Fatty acid oxidation in relation to cholesterol biosynthesis in rats. Lipids 1, 415-421.

Emken EA, Adlof RO, Rohwedder WK \& Gulley RM (1993) Influence of linoleic acid on desaturation and uptake of deuterium-labelled palmitic and stearic acids in humans. Biochimica et Biophysica Acta 1170, 173-181.

Folch JL, Lees M \& Sloane-Stanley GH (1957) A simple method for the isolation and purification of total lipides from animal tissues. Journal of Biological Chemistry 226, 497-509.

Frayn KN (1983) Calculation of substrate oxidation rates in vivo from gaseous exchange. Journal of Applied Physiology 55, E628-E634.

Goransson G (1965) The metabolism of fatty acids in the rat. VII. Lauric acid and myristic acid. Acta Physiologica Scandinavica 64, 383-386.

Gregory J, Foster K, Tyler H \& Wiseman M (1990) The Dietary and Nutritional Survey of British Adults. London: H. M. Stationery Office.

Gunstone FD, Harwood JL \& Padley FB (1994) The Lipid Handbook, 2nd ed. London: Chapman \& Hall.

Hegsted DM, McGandy RB, Myers ML \& Stare FJ (1965) Quantitative effects of dietary fat on serum cholesterol in man. American Journal of Clinical Nutrition 17, 281-295.

Jones AE (1996) The gastrointestinal handling and metabolic disposal of dietary lipid. PhD Thesis, University of Southampton.

Jones PJH (1994) Dietary linoleic, $\alpha$-linolenic and oleic acids are oxidised at similar rates in rats fed a diet containing these acids in equal proportions. Lipids 29, 491-495.

Jones PJH, Pencharz PB \& Clandinin MT (1985a) Absorption of ${ }^{13} \mathrm{C}$-labelled stearic, oleic and linoleic acids in humans: application to breath tests. Journal of Laboratory and Clinical Medicine 105, 647-652.

Jones PJH, Pencharz PB \& Clandinin MT (1985b) Whole body oxidation of dietary fatty acids: implications for energy utilization. American Journal of Clinical Nutrition 42, 769-777.

Karpe F (1997) Postprandial lipid metabolism in relation to coronary heart disease. Proceedings of the Nutrition Society 56, 671-678.

Keys AJ, Anderson JT \& Grande F (1957) Essential fatty acids, degree of unsaturation, and effect of corn (maize) oil on the serum-cholesterol level in man. Lancet 1, 66-68.

Keys AJ, Anderson JT \& Grande F (1965) Serum cholesterol response to changes in the diet. IV. Particular saturated fatty acids in the diet. Metabolism 14, 776-787.

Kirschner SL \& Harris RS (1961) The effects of chain length on the metabolism of saturated fatty acids by the rat. Journal of Nutrition 73, 397-402.

Kritchevsky D (1994) Stearic acid metabolism and atherogenesis: history. American Journal of Clinical Nutrition 60, Suppl., 997S-1001S.

Leyton J, Drury PJ \& Crawford MA (1987) Differential oxidation of saturated and unsaturated fatty acids in vivo in the rat. British Journal of Nutrition 57, 383-393.

Lynn WS \& Brown RH (1959) Oxidation and activation of unsaturated fatty acids. Archives of Biochemistry and Biophysics 81, 353-362.

Macdougall DE, Jones PJH, Vogt J, Phang PT \& Kitts DD (1996) Utilization of myristic and palmitic acid in humans fed different dietary fats. European Journal of Clinical Investigation 26, $755-762$.

Mead JF, Slaton WH \& Decker AB (1956) Metabolism of the essential fatty acids. II. The metabolism of stearate, oleate and linoleate by fat deficient and normal mice. Journal of Biological Chemistry 218, 401-407.

Murphy JL, Jones A, Brookes S \& Wootton SA (1995) The gastrointestinal handling and metabolism of $\left[1-{ }^{13} \mathrm{C}\right]$ palmitic acid in healthy women. Lipids 30, 291-298.

Murphy JL, Jones AE, Stolinski M \& Wootton SA (1997) Gastrointestinal handling of $\left[1-{ }^{13} \mathrm{C}\right]$ palmitic acid in healthy controls and patients with cystic fibrosis. Archives of Diseases in Childhood 76, 425-427.

Ockner RK, Pittman JP \& Yager JL (1972) Differences in the intestinal absorption of saturated and unsaturated long chain fatty acids. Gastroenterology 62, 981-991.

Schoeller DA, Klein PD, Maclean WC, Watkins JB \& Van Santen $\mathrm{E}$ (1981) Fecal ${ }^{13} \mathrm{C}$ analysis for the detection and quantitation of 
intestinal malabsorption. Journal of Laboratory and Clinical Medicine 97, 439-448.

Stolinski M, Murphy JL, Jones AE, Jackson AA \& Wootton SA (1997) Stable-isotope method for determining the gastrointestinal handling of $\left[1-{ }^{13} \mathrm{C}\right]$ palmitic acid. Lipids 32, 337-340.
Watkins JB, Klein PD, Schoeller DA, Kirschner BS, Park R \& Perman JA (1982) Diagnosis and differentiation of fat malabsorption in children using ${ }^{13} \mathrm{C}$-labelled lipids: trioctanoin, triolein and palmitic acid breath tests. Gastroenterology 82, 911917. 


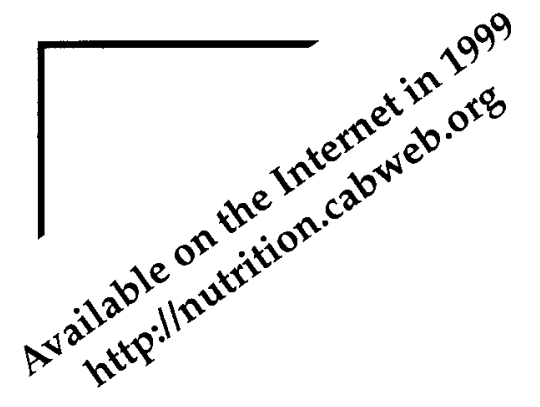

\section{Proceedings of the} Nutrition Society

\section{Editor: K M Younger Dublin, Ireland}

Throughout the year, the Nutrition Society holds important meetings and symposia, often in collaboration with other learned societies, where international experts are invited to speak on topics of particular interest in nutritional science.

The 1999 volume will feature papers and abstracts presented at Nutrition Society Symposia including:

- Meat or wheat for the next millennium?

- Effect of diet on lipoproteins involved in cardiovascular disease

- Bioavailability of micronutrients

- Optimal versus adequate nutrition

- Functionality of nutrients: behaviour, safety, gene expression and food technology

All this key information can be at your fingertips during 1999 by subscribing to the Proceedings of the Nutrition

Society.

Published quarterly

ISSN: $00296651 \quad$ 1999, Volume 58 $£ 240.00$ (US\$425.00 Americas only)

Order your 1999 subscription now!

\section{(1i) $C A B I$ Publishing}

CAB International

Wallingford, Oxon, OX10 8DE, UK

Tel: +44 (0)1491 832111

Fax: +44 (0)1491 829292

Email: publishing@cabi.org

(10) $C A B \mid$ Publishing

$\mathrm{CAB}$ International

10 East 40th Street, Suite 3203,

New York, NY 10016, USA

Tel: +1 (212) 4817018

Toll-free: 18005284841

Fax: +1 (212) 6867993

Email: cabi-nao@cabi.org 